its innervation is viâ the geniculate ganglion, great superficial petrosal nerve and sphenopalatine ganglion.

The narration of this case forms the basis for a speculative discussion on the rtiology of the condition in this instance, and in others of a similar nature with the usual review of the literature available to the author on the subject. Alex. R. Tweedie.

\title{
CORRESPONDENCE.
}

\section{THE INTRANASAL OPERATIVE TREATMENT OF FRONTAL SINUS SUPPURATION.}

\section{To the Editor of The Journal of Laryngorogy, Rhinology, and OTOLOGX.}

Sir,--May I draw attention to the absence of a description in the Official Reports of the demonstration on my intranasal methods, which I gave on August 11, 1913, at the International Congress of Medicine in London, in accordance with the official programme of the Laryngological Section.

The operation by "anterior entry," which I described and illustrated in the Jodrnal of Laryngology, Rhinology, and Otology, May, 1914, covers the ground of my demonstration at the International Congress; while a more recent demonstration, which I had the privilege of giving in the Laryngological Section of the British Medical Association Meeting at Aberdeen last July, is substantially the same, and hence hardly merits any further extended note in your reports of the proceedings of that meeting.
I have the honour to remain,
Yours faithfully,
September, 1914.
P. Watson-Williams.

\section{NOTES AND QUERIES. \\ Cocaine and Adrinalin during the War.}

We are obliged to Messrs. Duncan, Flockhart \& Co., and to Messrs. Parke, Davis \& Co. for the following information.

Cocaine.-The price of cocaine in England has advanced since the war broke out from 10s. to $15 \mathrm{~s}$. an ounce. This rise is chiefly due to the fact that the British Government has been purchasing large quantities of the drug. Cocaine is made from the coca leaf, which is cultivated in British India, Java, and South America, and supplies are expected shortly which will probably reduce the price of the drug. But a reduction to the figure prevailing prior to the outbreak of the war is highly improbable.

With regard to the synthetic local anæsthetics such as Novocaine, Eucaine, etc., the stocks in England are sufficient to meet all ordinary demands. Consequently, the price of these articles has risen but slightly. Although hitherto largely prepared abroad, steps have already been taken to manufacture them in England for the future.

The price of the suprarenal gland extracts (adrenalin, supra-renin, etc.) has not so far been affected by the war. 


\section{GENTRAL LONDON THROAT AND EAR HOSPITAL GRAY'S INN ROAD (Near King's Cross Stations).}

The work carried on at this Hospital comprises:

1. The Daily Out-Patient Olfinic.

The Medical Officers attend as follows:

$$
\text { Surgeons. }
$$

Mr. Chichere Nourse

Dr. Abercrombir

Mr. Stuart-Low

Dr. ANDRew WyLie .

Dr. AtKinson

Dr. DAN McKenzie

A ssistant Surgeon.

Mr. Harold Kisch
Out-Patient Clinic. Wednesday, at 2 p.m. Thursday, Saturday, Monday, Tuesday, Friday, at 2 p.m. . Monday, at 2.15 p.m. at 2 p.m. . Tuesday, at 2.15 p.m. at 5 p.m. . Thursday, at 2 p.m. at 5 p.m. . Thursday, at 4 p.m. Friday, Operations.

The Minor Operations.

'I'hese are performed at 9 a.m. on Monday, Tuesday, Wednesday, Thursday, Friday.

3.

\section{The In-Patient Department. Major Operations.}

These take place at 2 o'clock on Monday, Tuesday, Wednesday, Thursday, Friday.

'The list of operations is to be seen on the notice board in the Out-patient Consulting Room.

\section{Lectures and Demonstrations.}

Courses of Practical Instruction are given throughout the year by Members of the Staff, on 'I'uesdays and Fridays, at 3 p.m. punctually.

'T'he Courses consist of two classes twice a week devoted to Anatomy, Pathology, Diagnosis and Treatment of the special diseases dealt with at the Hospital. 'They may be joined at any time.

A Surgical Anatomy and Operative Surgery Class is held when desired. 'I'he teaching is practical and demonstrative, and is illustrated by diagrams, models, specimens and instruments.

5.

The Pathological Laboratory

Is at all times available to students. Dr. Wyatt Wingrave, Pathologist to the Hospital, is in attendance daily at 3 p.m.

\section{Clinical Assistants}

Are appointed from among those gentlemen who have enrolled themselves for attendance on the practice of the hospital.

Eurther particulars may be had on application to the Dean.

\section{Fees.}

$\begin{array}{llccc}\text { Course of Practical Instruction } & \ldots & \ldots & \ldots & 1 \text { guinea. } \\ \# ” & \text { with attendance at Clinics } & \mathbf{2} \text { guineas. } \\ \text { Operative Surgery Class } & \ldots & \ldots & \ldots & 5\end{array}$

For attendance on the practice of the Hospital (Clinical Assistants)-

$\begin{array}{llcl}\text { Three months } & \ldots & 5 & 5 \text { guineas. } \\ \text { Six } & \ldots & 8 & \\ \text { Perpetual ticket } & \ldots & 10 & \end{array}$

Clinical Assistants are admitted to the Practical Course Free.

WYATT WINGRAYE, M.D.,

Dean.
RICHARD KERBHAW, Secretary Superintendent. 


\section{WRIGHT, PubLISHERS, BRISTOL.}

Demy 8vo, with 77 Illustrations, 44 of which are in Colours. $7 / 6$ net.

Diseases of the

\section{THROAT,
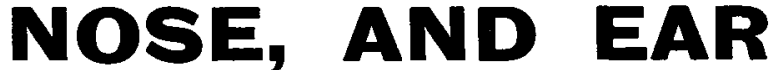

For Practitioners and Studente.

By W. G. PORTER, M.B., B.Sc., F.R.C.S.Ed.,

Surgeon to the Eye, Ear, and Throat Infirmary, Edinburgh; Surgeon, Ear and Throat Drpartment, Royal Hospital for Sick Children, Edinburgh; Aurist to the Edinburgh Royal lnstitution for the Education of the Deaf and Dumb.

“" The author's main object has been to provide the practitioner and serious student with a single volume of moderate size, embracing sufficient information on the diseases of the throat, nose, and ear, to be of value in practice. We may say at once that he has attained his object." - British Medical futurnal.

"Eminently suited to the purpose for which it is designed."-Fournal of Laryngningy.

"The several diseases are concisely deait with. . . The book as a whole reflects sound teaching, and recent literature has evidently been laid under contribution. It is well printed and well illustrated."-Lances.

"The work is eminently suited to the purpose for which it has been designed.. a large amount of well. digested and accurate information has been packed into a surprisingly small compass. Special attention has been given to diagnosis, and to such treatment as can be carried out successfully, by one who is not a specialist. . . We congratulate Dr. Porter upon producing a very excellent small manual."-Practitioner.

Originally published in 1912, the first Large Edition was exhausted in Six Months.

The second Impression was quickly sold out, and the Third Issue is now ready.

Demy 8vo. 1030 pages. With 16 Coloured Plates and over 200 Illustrations in the Text. Bevelled Boards, Burnished Top. $30 /$ net.

\section{AN INDEX OF DIFFERENTIAL DIAGNOSIS OF MAIN SYMPTOMS By Many Writers.}

Edited by HERBERT FRENCH, M.A., M.D.Oxon., F.R.C.P.Lond.

"May be said to represent the last word as to limits of diagnostic power . . . illustrations are of a uniformly high merit, and aid materially . . . of Dr. French's work, both as editor and contributor, we cannot speak too highly . . This remarkable index."-British Medical Journal.

"All that it is possible to learn of medicine in its various branches outside the wards of a hospital will be found in this book."-Practitioner.

6th Edition. 13th Thousand. Completely Revised, with additional Articles and Illustrations. Demy 8vo. 1056 pages. Bevelled Boards, Burnished Tops. 21/-net.

\section{AN INDEX OF TREATMENT \\ By 83 Representative Contributors.}

Edited by ROBERT HUTCHISON, M.D., F.R.C.P., Physician to the London Hospital.

A Complete Guide to Treatment in a Form Convenient for Reference.

"The editors and publishers may be congratulated on the production of a work of reference which we can cordially recommend to all busy practitioners." - British Medical fournal.

"The book is of special use to the general practitioner, who will tind in it many valuable suggestions for the management of disease."-Lancet.

"Handy, accurate. - easy of reference... we congratulate editors and contributors upon having added to medical literature a useful and comprehensive work."-Medical Press and Circular.

Now Ready. Fourth Edition, Fully Revised. Crown 8vo. 9/6 net. With Diagrams of Surface Markings.

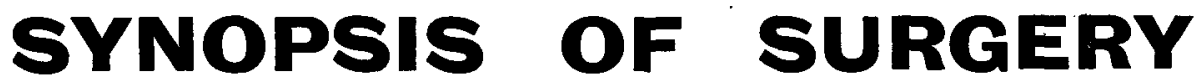

For Students and Practitioners.

By ERNEST W. HEY GROYES, M.S., M.D., B.Sc.Lond., F.R.C.S.Eng.

". * appears to contain all that is necessary in a synopsis, and . . . is not too condensed. . . may be legitimately employed for revising knowledge." - Lancet.

"The additions necessary to keep it quite up to date have been freely made... . . Among the best of its kind, and the author is to be congratulated on its readableness, its lucidity, and its fulness-notable qualities." British Medical Journal.

Bpistol : JOHN WRIGHT \& SONS, Limited.

London: SIMPKIN, MARSHALL, HAMILTON, KENT \& Co., Ltd. 


\section{MEDICAL GRADUATES' COLLEGE}

\section{AND \\ POLYCLINIC,}

22, Chenies Street, Gower Street, London, W.C.

PRESIDENT:

Sir JAMES CRICHTON-BROWNE, M.D., LL.D., F.R.S.

The teachers include members of the Staffs of the General and Special Hospitals and Medical Schools of the Metropolis and elsewhere.

The Demonstrations on Friday afternoons at 4 p.m. are devoted to Diseases of the Throat, Nose, Ear and Eye.

Lectures, October I 5th.-Mr. J. F. O'MALLEY.- "The Indications for the Removal of

Tonsils and Adenoids." October 2ist.-Dr. JoHN MACkeith._-"Laryngeal Tuberculosis."

Annual Subscription, admitting to all Lectures and Demonstrations, One Guinea.

Special Practical Classes are conducted in Otology (Dr. Dan McKenzie), Laryngology

(Mr. J. Gay French), and Rhinology (Mr. STUarT-Low), etc.

Pathological Investigations of all kinds are carried out in the Laboratory.

Further Particulars may be obtained from the Medical Superintendent, Major Vint, M.B., 22, Chenies Street, Gower Street, London, W C.

\section{Medical Temperance Review.}

Edited by H. J. PATERSON, M.B. QUARTERLY. Sixpence per Number met. ADLARD \& SON, BARTHOLOMEW CLOSE, LONDON, E.C.

\section{BRITISH JOURNAL OF CHILDREN'S DISEASES.}

Edited by J. D. ROLLESTON, M.D. MONTHLY. ANN. SUB. 20/- net, \$5, post free.

ADLARD \& SON, BARTHOLOMEW CLOSE, LONDON, E.C. 


\section{HOSPITAL FOR \\ DISEASES OF THE THROAT,}

GOLDEN SQUARE, LONDON, W.

HONORARY MEDICAL STAFF.

Consulting Surgeons $\left\{\begin{array}{l}\text { MR. MARK. HOVELL. } \\ \text { DR. LAMBERT LACK. }\end{array}\right.$

Surgeons. $\quad$ Out-Patients.

Mr. CHARLES PARKER $\ldots$

DR. FITZGERALD POWELL

Mr. FRANK ROSE ... ...

Mr. JEFFERSON FAULDER

Mr. GEORGE BADGEROW

Assistant Surgeons.

Mr. NORMAN PATTERSON

Mr. LIONEL COLLEDGE

Dental Surgeon.

Mr. PITTS $\ldots . \quad \ldots \quad$... Thursday, 9.30 A.M.

\begin{tabular}{|c|c|c|c|c|}
\hline & & & & \\
\hline Wed & 2.O P.M. & $\cdots$ & Friday, & $10.15 \mathrm{~A} . \mathrm{M}$ \\
\hline Tuesday, & 2.0 P.M. & $\cdots$ & $\because$ & 2.0 P.M. \\
\hline Monday, & 2.O P.M. & $\ldots$ & Thursday, & I $0.0 \mathrm{~A} . \mathrm{Mi}$ \\
\hline Thursday, & 2.0 P.M. & $\cdots$ & Fridar, & 2.0 P.M. \\
\hline$\left\{\begin{array}{l}\text { Tuesday, } \\
\text { Saturday, }\end{array}\right.$ & $\begin{array}{l}6.30 \text { P.M. } \\
2.0 \text { P.M. }\end{array}$ & $\begin{array}{l}\cdots \\
\ldots\end{array}$ & Tuesday, & $9.3 \circ \mathrm{A} . \mathrm{M}$. \\
\hline$\left\{\begin{array}{l}\text { Monday, } \\
\text { Friday, }\end{array}\right.$ & $\begin{array}{l}\text { 9.o A.M. } \\
\text { б.o P.M. }\end{array}$ & $\begin{array}{l}\cdots \\
\cdots\end{array}$ & Wednesday & $9.0 \mathrm{~A} . \mathrm{M}$. \\
\hline
\end{tabular}

Attendances.

Friday, 2.0 P.M.

Thursday, 2.0 P.M., Friday, 6.o P.м.

\section{CLINICAL INSTRUCTION.}

A Clinical Demonstration on the Diagnosis and Treatment of Selected Cases (Larynx, Nose, Ear) will be given each Monday at 5 p.m.

A Course in Surgical Anatomy and Physiology will be given each Thursday at 5 p.m. These Courses are free to Students of the Hospital. Others a fee of 2 guineas for each Course.

Practical Instruction in the Diagnosis and Treatment is given daily in the Out-patient Department from 2 to 5 p.m., on Tuesdays and Fridays from.6.30 p.m. to 9 p.m., and Mondays at 9.30 a.m.

Major Operations are performed at to a.m. on Tuesday, Wednesday, Thursday, Friday, and Saturday, and Fridays at 2 p.m.

Minor Operations daily (Mondays excepted) at $9.30 \mathrm{a} . \mathrm{m}$.

Operative Surgery Classes can be formed at any time on application.

Practice in Direct Laryngoscopy, Tracheoscopy, Bronchoscopy, and

Esophagoscopy will be given to Students, to enable them to become famiiiar with the use and manipulation of the instruments.

Practitioners and Medical Students are admitted to the Practice of the Hospital at a fee, of five guineas for three months, eight guineas for six months, or ten guineas for a Perpetual Studentship. Each course may commence at any date. Special terms to men in actual practice who can only attend the hospital once or twice a week.

The Hospital contains 60 beds for In-patients. There is also an Out-patient attendance of nearly 50,000 yearly.

Gentlemen may enter to the practice of The Throat Hospital at any time, and on certain conditions eligible for appointment as Clinical Assistants, whose duty it is to Assist the Member of the Staff to whom they are appointed.

GEORGE W. BADGEROW, F.R.C.S., Hon. Med. Sec. 


\section{MAYER \& MELTZER,}

Surgical Instrument Makers.

ESTABLISHED OVER FIFTY YEARS.

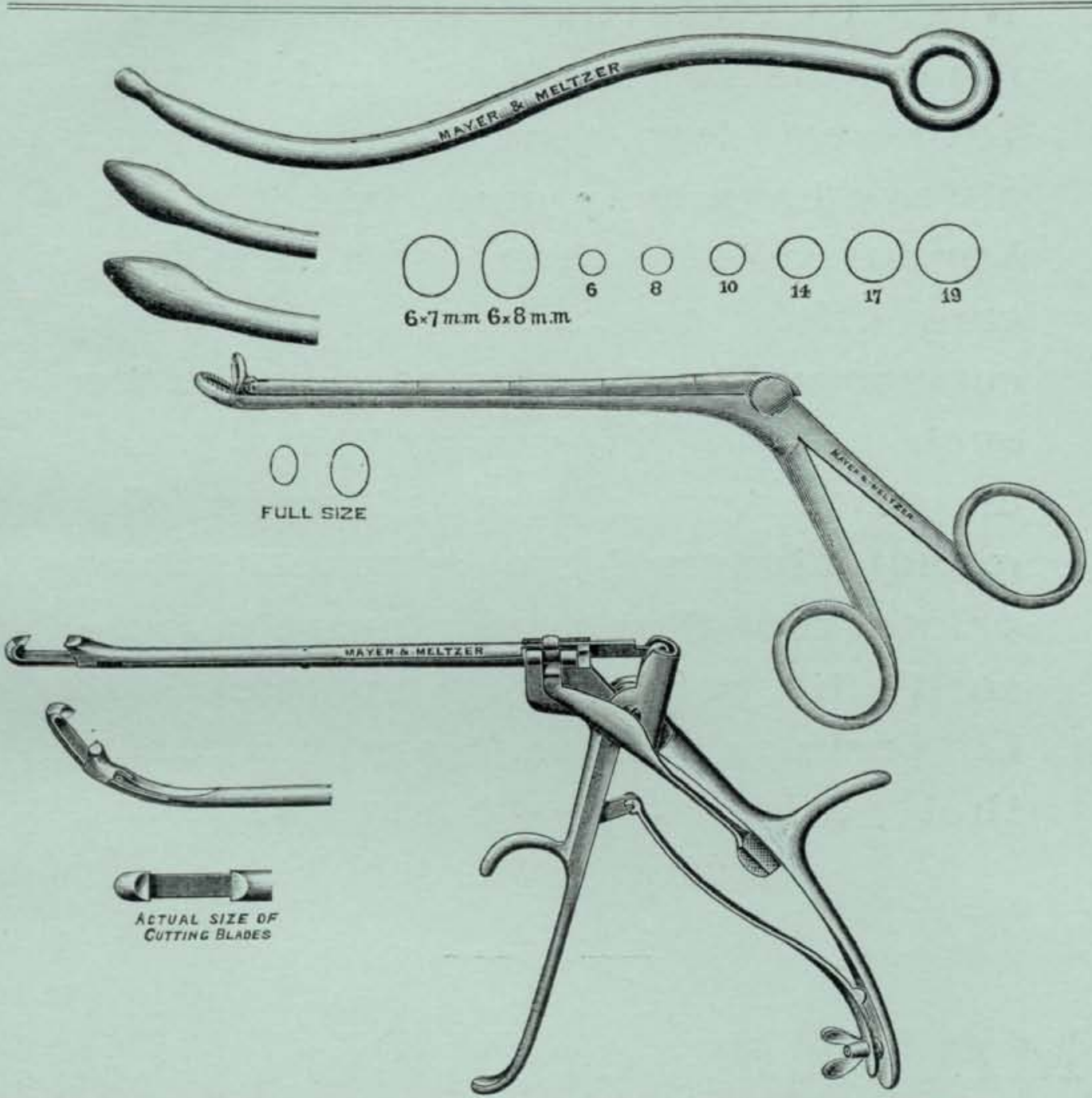

Instruments as used by Dr. Watson-Williams for the Intra-Nasal Operation for Frontal Sinus Suppuration.

(SEe JOURNAL OF LARYNGOLOGY, May, 1914.)

Full Particulars on application.

MAYER \& MELTZER, 71, GREAT PORTLAND ST., LONDON.

Branches: MELBOURNE; CAPE TOWN; JOHANNESBURG. 


\section{MAYER \& MELTZER}

Wish to state that all the instruments listed in their Catalogues, with very few exceptions, are and always have been made in their own London Workshops, so that they can offer customers their usual service without any rise in price for such goods. In sundry lines, such as glass and enamelled ware, the manufacturers have advanced their prices, so that these must necessarily be raised in proportion. It is perhaps unnecessary to state that partners, capital and staff are entirely British.

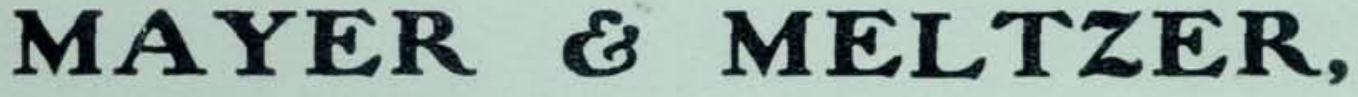

Surgical Instrument Makers.

ESTABLISHED OVER FIFTY YEARS.

71, Great Portland Street, LONDON. And at Melbourne, Cape Town, Johannesburg. 